\title{
INDEX OF CIRCULAR AGRICULTURE DEVELOPMENT IN THE REPUBLIC OF MACEDONIA
}

\author{
Nikola M. Trendov
}

Szent István University, Gödöllő, Hungary

In the Republic of Macedonia, the circular economy would boost country's agri-food sector competitiveness and help create new business and market opportunities for the farmers and processing industry. Public benefits that could accrue from the bio-economy perspective has become compelling. Nevertheless, the question arises: "At what level are we? Does the country go toward the development of the circular agriculture or not?" By using conceptual model of BPEIR (Behaviour - Pressure - Effect - Impact - Response) and Analytic Hierarchy Process (AHP) method, the author introduces a comprehensive analysis and quantitative evaluation of the level of Macedonian circular agriculture development. This paper discusses the fact that the Republic of Macedonia shows positive trends regarding circular economy disciplines in agriculture, given by natural geographic conditions and traditional agricultural production.

Keywords: circular economy, bio-economy, circular agriculture, the Republic of Macedonia

\section{Introduction}

By 2030, approximately three billion middle-class consumers will enter the global market, thus increasing the demand for goods and services and putting additional pressure on natural resources and energy supplies. Therefore, arise of urgent move towards a circular economy model of sustainable production and consumption patterns that covers entire product lifecycles through greater reduce, re-use and recycle and brings benefits for both the environment and the economy will be priority for the countries (Ellen MacArthur Foundation, 2013). The circular economic model is 'end-of-life' concept that tries to eliminate waste by designing materials, products, and systems in most efficient way as the most notable business models (Torok et al., 2015; Fonseca et al., 2010). Nowadays, a number of socio-economic instruments have been used to implement the principles of circular economy like the pollution tariffs, environmental taxes and eco-labelling, "3Rs" (Reduction, Reuse and Recycling), Life Cycle Assessments (LCAs) and environmental management tools for wastewater recycling and reuse (Lu et al., 2005; Hinton, 2008).

Europe has recognized the risks and the benefits of moving to a more resource-efficient society, as set out in the Europe 2020 strategy for smart, sustainable and inclusive growth (EC, 2010a). The aim of this strategy is to set the overarching framework that gathers related initiatives that promote a more sustainable and resource efficient EU. Diversified sectoral policies have been put in place at EU level, which support the development of a bioeconomy concept. It includes the Biodiversity Strategy (EC, 2011b), whose main aim is to refer to the maintenance of the natural capital and resources as a critical economic asset (Mazza and ten Brink, 2012).

How should this circular economy develop to the stage where whatever is done works effectively and well in case of the Republic of Macedonia? This question requires further examination and research of the issues related to sustainability of economy. Such an investigation has not taken place, especially in the Republic of Macedonia. There is a need to explore this in aspect of the bio-economy. The bio-economy in the $21^{\text {st }}$ century can be interpreted the way the fossil-based economy was in the $20^{\text {th }}$ century (Kulshreshtha et al. 2011). The bio-economy enables the efficient use of renewable resources in the form of agricultural inputs - and partially outputs. The food demand growth in the future will have to be met essentially by increasing the productivity of the cultivated land through yield increases (Cuffaro, 2003). Water, nutrients, soil, wind, and solar energy are the key factors for the food production. By using these resources and utilizing their value, the bio-economy places itself directly in the core of the circular economy. It helps to reduce the use of fossil raw materials, $\mathrm{CO}_{2}$ emissions and wastewater quantity, but not at the same level as can be experienced in other sectors due to food market insecurities and production limitations (Fogarassy and Nabradi, 2015). At the same time, agriculture will continue to provide food and animal feed that are healthy and safe (Kulshreshtha et al., 2011).

In the Republic of Macedonia, the circular economy perspective which is based on bio-economy principles - would boost country's agrifood sector competitiveness and help create new business and market opportunities for the farmers and processing industry. Therefore, the concept of "circular agriculture" applies the principles of the bio-economy to the entire agricultural production. It is an entirely new concept and set of strategies, an improved approach to agricultural economy that addresses the coordinated development of populations, resources and the environment (Geng et al., 2008). As a low-input, high-recycling, high-efficiency, high-technology and industrialized set of practices, 'circular agriculture' is distinct from the conventional and traditional agriculture and represents the revolution in the sector (Tang and Yin, 2006). It could create jobs, foster rural youth employment, mitigation and gender mainstreaming. At the same time, it can lead to energy savings and reduce the use of natural resources, especially in a small and lockland country like the Republic of Macedonia. The public benefits that could accrue from the circular agriculture perspective have become compelling. Nevertheless, the question arises: "At what level are we? Does the country go toward the development of the circular agriculture or not?"

\section{Methodology of the index system evaluation}

By using conceptual model of BPEIR (Behaviour - Pressure - Effect - Impact Response) established by Fang et al. (2005) and Analytic Hierarchy Process (AHP) Method described by Saaty (1980), the author conducts comprehensive analysis and quantitative evaluation of the level of Macedonian circular agriculture development. Therefore, the author conducts an analysis of Macedonian bio-economy development, based on the findings of the quantitative evaluation. At same time, the principles of circular economy are included. 
According to the conceptual connotation of bio-economy, the author conducts quantitative evaluation regarding the level of circularity in agriculture from the viewpoint of four aspects: socio-economic development, reduction in quantity of inputs required in the agri-food sector (in particular those that cannot be recycled), recycling and reprocessing agricultural inputs; and ensuring biodiversity and environmental protection. Taking into consideration the lack of data and the fact that country's latest agricultural censuses were released in 2007 and 2013, data availability and reliability was difficult to structure. The analysed data for the 2006-2015 period was partly adjusted for the research needs by using linear trend between the last two agricultural censuses as there were no data available partially for given indices in given years.

Thus, based on data availability and reliability, the established detailed index system contains five index measurements per each aspect of circular agriculture for the Republic of Macedonia. For the socio-economic development, the author selected five indices: agricultural GDP, farmers' per capita net income, utilized agricultural area (UAA) output rate, rate of grain output per capita and commercialization rate of livestock products. In terms of reducing the inputs, the following concepts were selected: the total horsepower of household farm machinery, UAA under organic production, level of fertiliser use, involved agricultural labour force and amount of utilized water for irrigation. These five indices were selected for recycling and reprocessing: level of pesticide use, multiple crop index rate, level of fertiliser use, effective coefficient of used fertilisers and agri-food sector wastewater discharge rate. The evaluation of the fourth aspect included effective irrigation rate, forest coverage rate, UAA per capita, rate of $\mathrm{CO}_{2}$ emission in agriculture and agri-food water for production rate. Therefore, the author uses
AHP Method and similar approach to Zhang et al. (2003), to assign weight to the composed index system. Standardization of the raw data was made by the following method:

Positive Index:

$$
X_{i j}=X_{i j} / X_{i}
$$

Negative Index:

$$
X_{i j}=X_{i} / X_{i j}
$$

where:

$X_{i i} \quad$ - original value of the index

$X^{\prime \prime} \quad$ - the standardized value of the index

$X_{i} \quad$ - the original value of $C n$ indices of circular economy development within the Macedonian agriculture

Hereafter, a comprehensive assessment of circular agriculture in the Republic of Macedonia, and the calculation model (Formula 3) were made to understand its development:

$$
Z=\sum_{j=0}^{4}\left(\sum_{j=0}^{n} X_{j} \times W_{j}\right) \times R_{j}
$$

where:

Z - a comprehensive evaluation index showing the development of circular agriculture in the Republic of Macedonia

\begin{tabular}{|c|c|c|c|}
\hline Classified Index A & Specified Index B & Index weight & Index description \\
\hline \multirow{5}{*}{ 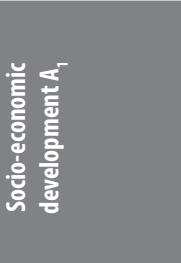 } & $\mathrm{B}_{1} \mathrm{MKD} \times 10^{7} / /$ agriculture GDP & 0.23 & agricultural GDP \\
\hline & $B_{2}$ farmers' per capita net income & 0.69 & household expenditure per capita / total farmers' per capita net income \\
\hline & $\mathrm{B}_{3}$ grain output per capita // Kg/people & 0.25 & total population / grain output (wheat, corn, barley) \\
\hline & $\mathrm{B}_{4}$ output rate of agriculture area $/ / \mathrm{ha} / 10^{6} \times \mathrm{MKD}$ & 0.14 & total UAA / agriculture output value \\
\hline & $B_{5}$ commercialization rate of livestock productions // $/$ MKD & 0.01 & total meat output / total value of animal husbandry output \\
\hline \multirow{5}{*}{ 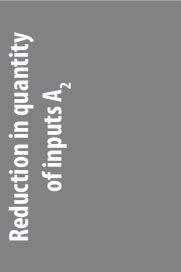 } & $\mathrm{B}_{6}$ horsepower rate per farm household $\mathrm{kW}$ & 0.09 & number of agri-households / total kW in agri-food sector \\
\hline & $B_{7}$ used degree of fertilisers // $t /$ ha & 0.03 & total amount of fertilisers / total area treated with fertilisers \\
\hline & $\mathrm{B}_{8}$ agricultural labour force $/ / 10^{6}$ & 0.45 & labour force engaged in agriculture, forestry and fishery \\
\hline & $\mathrm{B}_{9}$ UAA under organic $/ / \%$ & 0.24 & UAA under organic / total UAA \\
\hline & $\mathrm{B}_{10}$ agricultural use of water $/ / \mathrm{m}^{3}$ & 0.26 & irrigation water withdrawal $\left(10^{9} \mathrm{~m}^{3} /\right.$ year $)$ / agriculture in GDP $\left(10^{6} \mathrm{MKD}\right)$ \\
\hline \multirow{5}{*}{ 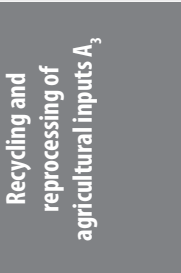 } & $B_{11}$ multiple crop index // \% & 0.30 & UAA under crops / total UAA \\
\hline & $\mathrm{B}_{12}$ pesticide use level // ha / $10^{6} \mathrm{MKD}$ & 0.16 & UAA treated with pesticide / total pesticide value $\left(10^{6} \mathrm{MKD}\right)$ \\
\hline & $\mathrm{B}_{13}$ level of organic fertilisers $/ / \%$ & 0.35 & UAA under organic fertilisers / total UAA \\
\hline & $B_{14}$ effective use coefficient of fertilisers $10^{6} \mathrm{MKD} / \mathrm{t}$ & 0.08 & total agriculture output value $\left(10^{6} \mathrm{MKD}\right)$ / amount of fertilisers \\
\hline & $\mathrm{B}_{15}$ agri-food sector wastewater discharge rate // \% & 0.58 & agri-food sector wastewater discharge $\left(10^{3} \mathrm{~m}^{3}\right)$ / total manufacturing wastewater discharge $\left(10^{3} \mathrm{~m}^{3}\right)$ \\
\hline \multirow{5}{*}{ 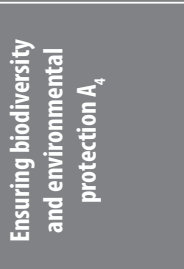 } & $\mathrm{B}_{16}$ forest coverage rate $/ / \%$ & 0.38 & total forest area / total area of land \\
\hline & $\mathrm{B}_{17}$ effective irrigation rate $/ / \%$ & 0.23 & effective irrigation area / total UAA \\
\hline & B 18 per capita UAA // ha / person & 0.25 & total UAA / total population \\
\hline & $\mathrm{B}_{19}$ agri-food sector water for production rate $/ / \%$ & 0.55 & agri-food sector water for production $\left(10^{3} \mathrm{~m}^{3}\right)$ / total manufacturing water for production $\left(10^{3} \mathrm{~m}^{3}\right)$ \\
\hline & $\mathrm{B}_{20} \mathrm{CO}_{2}$ emission in agriculture $/ / \mathrm{t} \times 10^{3}$ & 0.10 & $\mathrm{CO}_{2}$ emission in agri-food sector / total $\mathrm{CO}_{2}$ emission \\
\hline
\end{tabular}

$\sum_{j=0}^{n} X_{j} W_{j}$ - value of all classified evaluated indices

Table 1 Comprehensive evaluation index system and index weight of circular agriculture in the Republic of Macedonia (2006-2015)

Source: Self-made, based on author's own calculations, 2017 
$X_{j} \quad$ - standardized value of the $j$ th specified $B$ index which is subordinate to $i$ th classified $A$ index

$W_{j} \quad$ - the corresponding weight of the jth specified $B$ index which is subordinate to the ith classified $A$ index

$R_{j} \quad$ - the weight of the ith specified $B$ index

\section{Evaluation of the results and analyses}

The comprehensive evaluation index was analysed based on data from 2006-2015 period according to the elaborated method. The comprehensive evaluation index of the circular agriculture in the Republic of Macedonia shows slight progress in the last 10 years, although there are many variations between certain periods. Figure 1 divides the circular development of the Republic of Macedonia into two stages. The first stage (2006-2010) is the rising stage and the growth rate of circular agriculture development level increased by 0.1 index point. This interval is characterized as the period of EU agricultural transition for the Macedonian agriculture. Most of the agri-food sectors started EU funded programmes and approached EU harmonization level. Socio-economic level increased, as many governmental projects addressed the rural areas and capacity building of the agri-food stakeholders. Therefore, good agriculture practices have been implemented in farms that contributed to the significant reduction in fertiliser and pesticide usage on fields. This time was also the start of organic farming promotion.

The second stage (2011-2015) shows decline and large variation of the circularity in agri-food sector. Promotion of direct payments and progressive subsidy scheme by the government led many farmers to increase their production and extend their fields and to benefit more from the governmental support. Increased amount of fertiliser and pesticide usage for massive production sent the circular agriculture development back, from 0.3 index point level in 2010 to 0.2 index point level in 2014. The large

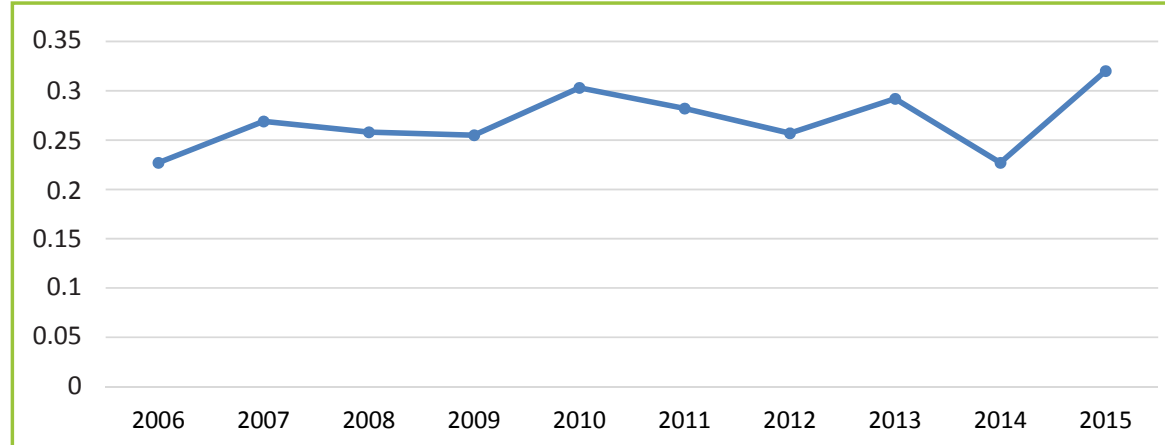

Figure 1 Comprehensive Evaluation Index of the circular agriculture development in the Republic of Macedonia (2006-2015)

Source: Self-made, based on author's own calculations, 2017

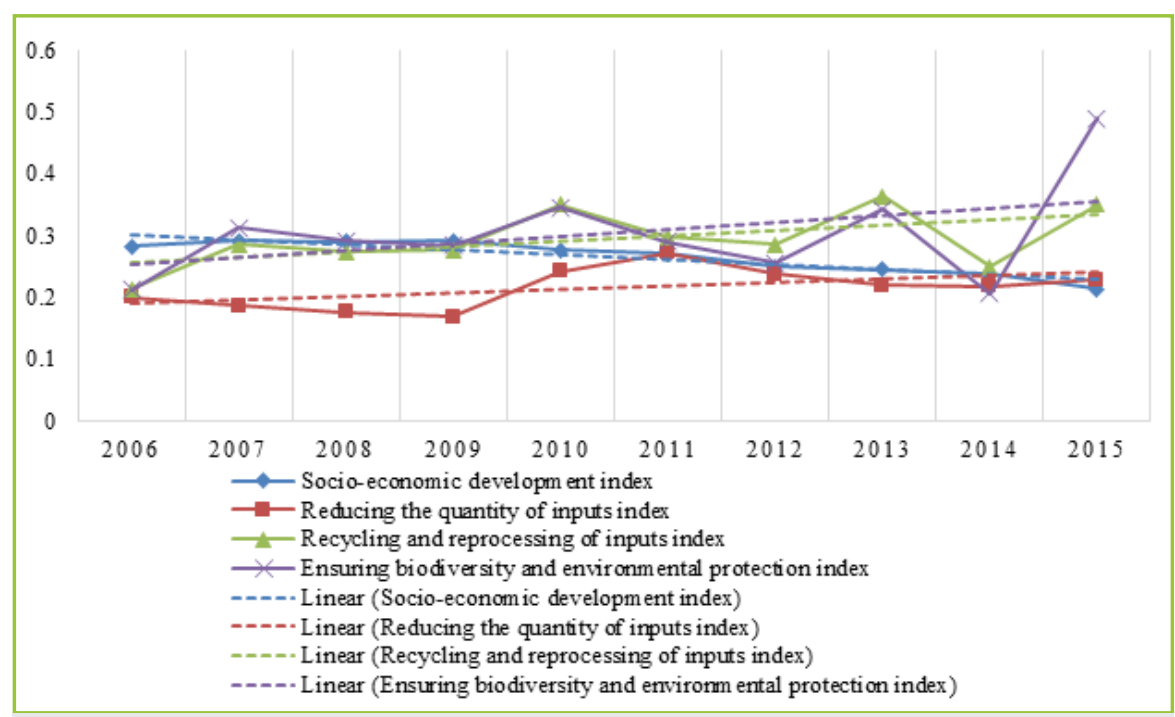

Figure 2 Specified evaluation of circular agriculture development indices in the Republic of Macedonia (2006-2015)

Source: Self-made, based on author's own calculations, 2017 variation was the result of big differences in the use of fertilisers and pesticides applied by smallscale farmers and large agri-food companies. The input intensity of the latter highly surpasses the same rate of the former. In time of low yields, small-scale farmers cannot afford to purchase quality fertilisers or pesticides for next season due to bad weather conditions. Thus, they apply large quantity of inefficient and low quality inputs as the purchasing price of them is affordable for the small-scale farmers This pattern made them the key factor for these variations in the comprehensive evaluation index.

The evaluation index of socio-economic development (Figure 2) shows a linear declination trend (as the only measure within the four specified indices) with a drop of 0.06 index point. This is a bad pre-sign for the development of circular agriculture in the country. The shrinking trend is significant after 2009. It was the year when the heavily subsidized agricultural programmes showed their first effects and outputs in the agri-food sector. Even the economic growth of the country was positive during the last decade. The socio-economic development in terms of bioeconomy is lagging behind.

Index of reduction in quantity of agricultural inputs showed a positive continuous upward trend within the evaluation. With average growth of 0.02 index point in the last decade, the measure proves that reduction level of agricultural inputs on the farms decreased. Significant increase of this index is between 2009 and 2010. This period is characterized by the introduction of EU pre-accession funds for the local farmers in order to apply good agricultural practices and approach the EU level of farming by following the legislations of the Common Agricultural Policy. The improvement occurred due to the low initial level of people's awareness regarding resource conservation that was the result of education matters and agricultural policies from the former socialist system.

Long-term strategy for agriculture and rural development based on preference for subsiding production and quantity makes Macedonian farmers (especially those $0.1 \%$ large-scale agrifood companies) maintain "the socialist habit" of mass and managed production. In such process farmers massively produce, consume and waste which leads to less or low-level efficiency in terms of recycling and reprocessing the agricultural inputs. However, Macedonian farmers show progress from 2006 onward with some variations in the last five years. The index point rises from 0.21 in 2006 to 0.30 in 2015, with top peak of 0.36 index point in 2013. 
The government has launched a massive campaign last few years to stress the effects of the climate change and its impact on biodiversity. Many measures were taken and laws were passed to cope with global threats of the changes. According to the evaluation index dealing with ensuring biodiversity and environmental protection, the Republic of Macedonia is on the right track facing these changes regarding agriculture. As illustrated in Figure 2, this index shows a positive trend with nearly 0.5 index point increase in the last decade. Ensuring biodiversity and environmental protection is a key factor in promotion and development of modern circular agriculture.

\section{Conclusion}

The analysis of this paper shows that the Republic of Macedonia has good preconditions given by natural geographic conditions, traditional production and infrastructure for being able to convert to circular agriculture. Due to rapid growth of biodiversity and environmental protection followed by positive changes in reducing, re-using and recycling the agricultural inputs, the agricultural circular economic development level has risen in the Republic of Macedonia in the last decade. However, the elaboration on governmental law and strategy is inevitable in order to approach the EU level. Not just in terms of bio-economy or circular agriculture, but from the viewpoint of overall concept of circular economy. Some EU member states have already developed a national strategy for bio-economy and concrete focus on circular agriculture. Countries like Germany and Finland have taken a wider approach to the bioeconomy as a whole, while other nations such as Sweden, the Netherlands and some regions in France place the emphasis on the bio-based economy.

As a predominantly agricultural country using its own natural resources for agri-food production, the Republic of Macedonia should foster the circular approach by enhancing productivity while making efficient use of available natural resources. This is always framed within an integral national policy. The Netherlands places the emphasis on biomass production, innovation and sustainability, while Sweden focuses on innovation, marketing and support for SMEs. Germany focuses on economy, innovation, education and policy. In the case of the Republic of Macedonia, introducing innovations like the precision agriculture technology and support of the small-scale farmers are key factors for circular agriculture.

The responsible use of natural resources, agricultural inputs, water and their efficient management must be promoted further to the farmers. Conservation of valuable landscapes, biodiversity and climate change mitigation must be in the forefront of the Macedonian policy makers' agenda aligned with the EU bio-economy strategy. Integrated farming systems that allow the reduction of external inputs such as fertilisers, energy and plant protection products must attract more attention. Development of circular agriculture may offer inherent opportunities for increased use of biomass raw materials within the agri-food and other manufacturing sectors.

However, according to the comprehensive evaluation index, the development of Macedonian circular agriculture faces disadvantages compared to the EU 28 level such as higher land and energy costs and lower political support, funding and incentives. These could be tackled by the revaluation of policy and support at national level with public and EU funds.

\section{References}

CUFFARO, N. 2003. Population, Economic Growth and Agriculture in Less Developed Countries. Taylor \& Francis e-Library, Master thesis, 2003, pp. 133-147.

EC. 2010a. Europe 2020 - European strategy for smart, sustainable and inclusive growth. Communication from the Commission to the European Parliament, the Council, the
European Economic and Social Committee and the Committee of the Regions, COM (2010) 2020.

EC. 2011b. Our life Insurance, Our Natural Capital: An EU Biodiversity Strategy to 2020. Communication from the Commission to the European Parliament, the Council, the European Economic and Social Committee and the Committee of the Regions, COM (2011) 244 Final.

FANG, M.Q. - HUANG, X.J. - PENG, B.Z. et al. 2005. A positive study of the evaluation on the development of regional agricultural recycling economy. In Journal of natural resources, vol. 20, 2005, no. 6, pp. 891-899.

FOGARASSY, CS. - NABRADI, A. 2015. Proposals for low-carbon agriculture production strategies between 2020 and 2030 in Hungary. Applied Studies in Agribusiness and Commerce - APSTRACT, vol. 9, 2015, no. 4. pp. 5-16. http://dx.doi.org/10.19041/ APSTRACT/2015/4/1

FONSECA, M. B. - BURRELL, A. - GAY, H. - HENSELER, M. - KAVALLARI, A. - M'BAREK, R. - DOMÍNGUEZ, I. P. - TONINI, A. 2010. Impacts of the EU biofuel target on agricultural markets and land use: a comparative modelling assessment. European Commission, Joint Research Centre, Seville, Spain, 2010.

GENG, Y. - ZHU, Q. - DOBERSTEIN, B. - FUJITA, T. 2008. Implementing China's circular economy concept at the regional level: A review of progress in Dalian, China, Waste Management, 2008, pp. 1-7. doi:10.1016/j.wasman.2008.06.036

HINTON, J. 2008. Is the circular economy ambitious enough? A look at incorporating PSS (product-service systems) into China's leapfrog development strategy. International Institute for Industrial Environmental Economics; Lund University. Master dissertation, 2008, pp. 3-6.

KULSHRESHTHA, S. - McCONKEY, B.G. - DYER, J.A. et al. 2011. Bio-based EconomySustainable Use of Agricultural Resources, InTech Open Access Publisher : Rijeka, 2011.

LU, X. - WANG, S. - HU, J. 2005. Government interventions in developing a circular economy- what can China learn from Sweden? International Business Program. Kristianstad University. Master dissertation, 2005, pp. 7-37.

MAZZA, L. - ten BRINK, P. 2012. Green economy in the European Union, UNEP, May 2012.

ELLEN MACARTHUR FOUNDATION (eds.). 2013. Towards the circular economy. Economic and Business Rationale for an Accelerated Transition, Ellen MacArthur Foundation : Cowes, 2013.

SAATY, T.L. 1980. The Analytic Hierarchy Process. New York : McGraw-Hill, 1980.

TANG, H. - YIN, C. 2006. Models and strategies for the development of circular agriculture in china. Workshop on Environment, Resources, and Agricultural Policies in China 19-21 June 2006, Beijing, pp. 1-10. Available at: http://www.oecd.org/ dataoecd/5/8/36786150.pdf

TOROK, T. - SZABO, Z. L. - ZSARNOCZAI, J. S. 2015. Methane reductions to moderate the global warming effects. Applied Studies in Agribusiness and Commerce - APSTRACT, vol. 9, 2015, no. 4, pp. 59-64. http://dx.doi.org/10.19041/APSTRACT/2015/4/8

ZHANG, F.R. - WANG, J. - CHEN, B.M. et al. 2003. Evaluation system and ways of land sustainable use, China Agriculture Press : Beijing, 2003.

\section{Contact address}

Trendov M. Nikola, Szent Istvan University, Doctoral School for Management and Business Administration, Faculty of Economics and Social Sciences, Páter Károly utca 1, H-2100 Gödöllő, Hungary, e-mail: trendov.nikola@gmail.com 